\title{
Enhancing Iranian EFL Learners' Descriptive Writing Through a Genre-based Pedagogy
}

\author{
Mahsa Assadi* \\ Ershad Damavand University, Tehran, Iran \\ Corresponding Author: Mahsa Assadi, E-mail: m.asadi10@gmail.com
}

\section{ARTICLE INFO \\ Article history \\ Received: May 15, 2018 \\ Accepted: August 09, 2018 \\ Published: November 01, 2018 \\ Volume: 7 Issue: 6 \\ Advance access: September 2018}

Conflicts of interest: None

Funding: None

\begin{abstract}
The present study is an investigation to study the influence of genre-based instruction on Iranian EFL learners' descriptive writing. After applying an OPT, 60 out of 80 Iranian EFL M.A. male and female students from two Azad universities in Tehran, Iran, were selected as the main participants of the current study. The qualified participants were randomly divided into one experimental group and one control group each with 30 learners. The experimental group had the genres based instruction on descriptive writing. The treatment was given in 16 sequential sessions about 30 minutes at the beginning of each session. The control group received no special treatment and it was taught based on traditional methodology of writing instruction. At the initial stage of the experiment, to estimate participants' knowledge at the beginning of the study, a pretest on writing performance was run to all participants. In this test, the two groups must write two compositions about the same topics. At the end of the study, a posttest was applied to check the participants' descriptive writing after having instruction. The participants' scores on the pretest and posttest were compared to estimate the degree of participants' progress within the group, and also the scores of the two groups were compared with each other to measure the function of instruction. The analysis of the results presented that learners in both groups had the same ability but learners in experimental group outperformed than learners in control group and it was concluded that genres based instruction as treatment worked well. The findings of this study are useful for learners to improve their writing skills. Another significance of this study is to build learners' confidence to echo their voice in the international educational contexts and to publish their articles in famous worldwide journals.
\end{abstract}

Key words: Descriptive Writing, Genre-based Pedagogy, International Educational Contexts

\section{INTRODUCTION}

\section{Overview}

This research wants to investigate the usefulness of a genre-based instruction to develop EFL learners' writing skills, the genre of descriptive writing has been chosen for this study. Writing is one of the most complex human activities. It consists of the development of a design idea, the use of mental representation of knowledge, and of experience with topic. Nowadays, in educational context, all university students in different majors require to progress their writing skills to have communication with international scientific and technological communities. For having this purpose, this study attempts to help the university students to develop insight about the concept of writing in a new perspective.

Genre- based approaches are being applied in ESL/EFL approaches so that they are considered as one of the important features in the last two decades in the field of applied linguistics (Rodgers,2001). Also, Hyland (2007) considers that genre approaches have considerable effect on the use of language and on literacy education. Genre-based instruction is used for explicit instruction of moves and steps in accordance to lexico-grammatical features which are common in them. The purpose of this study is to provide collaboration between teachers and learners to make writing as a dynamic process that causes learners engage with the real texts to progress their writing skill and make it as a longtime learning.

The descriptive genre is chosen for this study because it is necessary for university students who need to describe different types of charts, diagrams, procedures, places, objects and their emotions and experiences in their descriptive writings. This study is according to Feez (1998)' model of teaching and learning cycles. She expressed her model of genre teaching and learning cycles in five steps: 1-building the context, 2-modeling and deconstruction of text, 3-joint construction of text, 4-independent construction of text and, 5-linking related texts. This model wants to contextualize the writing tasks and led the learners to comprehend the framework of different types of texts that they have in classroom contexts in their real life. 


\section{Statement of the Problem}

Limited exposure to English especially in foreign context (EFL, in Iran) cause that learners have limited confidence in writing in English. This may be related to using test-driven learning and traditional approaches for teaching writing that cause them to ignore the main process of writing in this situation. Really, they write to practice grammar for having high scores on exams and when they are asked to write; they have a lot of problems in writing such as choosing appropriate words, the correct grammar, producing ideas and progressing them to have a proper organizational pattern.

The main point is that they have problem in applying an appropriate writing design that is according to a target language and society, and they strive to use appropriate language forms for different writing aims. So it is necessary for EFL learners to learn a general knowledge of writing in different genres to express their ideas in writings. It is essential to change the product-based approach to process-based approach to develop the learners' writing ability. Some researches asserted that writing is a tedious activity for learners because there is not any practical model to make better teaching writing skills, and a model to develop active learning in the classroom. This study wants to provide ideas into how to help learners learn an informed way to engage and analyses texts. This study investigated the value of explicit teaching of genre by this aim to help the learners to become more aware of how writers construct texts, and how they connect their texts to authentic contexts.

\section{Significance of the Study}

The present study is according to Feez (1998)' model of the genre-based cycle. She had used this model in her teaching methodology and the usefulness of its use is clearly protected by some other researchers (Joyce 1998, Rothery 1996, Hyon 1996 and Hyland 2007). Basic elements that make this model are Building the context, Modelling and deconstruction of the text, Joint construction of text, Independent construction of text and Linking to related texts. Though some studies studies have clearly mapped out the use of the model and detailed the activities did under each step and the usefulness of its use is supported, assessment of the activities applied in class seem to be lacking. This model of teaching writing provides chances for the learners to be engaged with different texts types and help them to take part in composing writing collaboratively with their teachers and their classmates to be according to the requirement of academic writing.

The genre of descriptive writing has been chosen for this study to help the learners to develop their writing skills to achieve the main purpose of their study. As writing skill is one of the main and indispensable part of university activities, this study emphasizes on uplifting the learners' abilities to write to reach the aims of their field of study. Another important element of this study is to increase learners' confidence to express their voice in the international educational contexts and to publish their articles in popular worldwide journals.

\section{Purpose of the Study}

This study is a try to investigate the influence of genre-based teaching on Iranian EFL learners' descriptive writing. This is a mixed method research and it wants to identify the usefulness of genre-based teaching to teach academic writing to university students who want to develop their writing ability. The descriptive writing is chosen, because it is a type of writing that students require for their academic writing tasks. The comparison will be made between using traditional model of teaching writing and the genre-based model of teaching to conclude whether this model has got any significant influence on improving the writing ability of university students or not. So, the main purpose of this study is to compare the product approach in terms of their influence on learners' academic writing.

\section{Research Questions}

1. Does the genre-based instruction have any significant effect on university students' descriptive writing?

\section{Research Hypotheses}

H0 (1): The Genre- based instruction doesn't have any significant effect on university students' descriptive writing.

\section{LITERATURE REVIEW}

\section{Theoretical Background}

"The essence of the concept of genre as now used in applied linguistics, ESP, and Rhetoric, is an emphasis on the primary of communicative purpose and the ways in which communicative needs shape or influence both surface form and deeper Rhetorical structure" (Holmes, 1997, p.322).

Some researchers express that genres have an active nature. Fahnestock (1997, p.270) expressed that "they are not field algorithms "and because "a genre is mean of achieving a communicative goal that has evolved in response to particular rhetorical needs it will change and evolve in response to changes in these needs" (cited by Dudley-Evan 1994.p.219). Bhatia (1997) defined "genres in terms of the use of language in conventional communicative settings and he goes and says that "they are meant to serve the goals of specific discourse communities, and in so doing, they tend to establish relatively stable structure forms and, to some extent, even constrain the use of lexico-grammatical resources "(p.181).

John Swales has been the most authoritative figure in the field of English for specific purposes, and the most helpful definition of genre is provided by him in 1990.So, in this section the researcher use Swales (1990) definition to clarify the concept of genre.

"A genre comprises a class of communicative events, the members of which share some of communicative purposes. These purposes are recognized by the expert members of the parent discourse community, and thereby constitute the rational for the genre. The rational shapes the schemat- 
ic structure of the discourse and influences and constrains choice of content and style. Communicative purposed on is both a privileged criterion and that operates to keep the scope of a genre as here conceived focused on comparable rhetorical action. In addition to purpose, exemplars of genre exhibit various pattern of similarity in terms of structure, style, content and intended audience" (p.58).

\section{Genre Theories}

Hyon (1996) expresses that many researchers in ESP courses (English for specific purposes) consider genre as an instrument for teaching spoken and written language need of non-native speakers. Some researchers such as (Bhatia 1993; Flowerdew 1993; Nawagu 1991; Swales 1990; Thompson 1994; Weisberg 1993) define genres by considering their formal characteristics or by their communicative purposes within social context. Swales defines genres as "communicative" events which include both "communicative purposes" and "structure, style content and intended audience" (1990 a.p.58). Some ESP researchers pay attention to the formal features of genre than the function of the text and their social contexts. Some others focus on grammatical features such as verb tense, hedges, etc. (Hanaia \& Akhtar 1985; Salager-Meyer 1994; Swales 1990; Tarone, Dwyer, and Gillette, Lcke 1981).

New rhetoric studies show a different method for analyzing genre (Hyon 1998). Researchers in these parts pay more attention to "the situation context in which genres occur than on their forms and have placed special emphasis on the social purposes, or actions, that these genres fulfill within these situations (Hyon 1998.p.696). Miller (1984, p.151) argues," a rhetorically sound definition of genre must be centered not on the substance or the form of discourse but on the action it is used to accomplish". Hyon also believes "that many proponents of New Rhetoric studied have used ethnographic rather than linguistic method for analyzing texts" (p.696).

Another theory is "Australian Genre Theory". It was at the same time of ESP and new rhetoric studies but it is different and independent of both. Australian approaches are related to systematic functional linguistic as language theory which is expressed by Michael Halliday. As Hyon (1996) expresses "systematic functional linguistic is concerned with the relationship between language and its function in social settings" (p.696), and it is said that the forms of languages are shaped by the main elements of social context. "The key features are; field (the activity going on), tenor (the relationship between the participants), and mode (the channel of communication)" (p.697). So, it can be concluded that Halliday defined genre as "in which the configuration of textual features comes together", (quoted in Flowerdew 1993.p.308).

The three features of field, tenor, and mode are used to recognize discourse structure and choice of linguistics realization. So, according to this view "Genre analysis is the study of how the contextual parameters, discourse structure, and language interrelate" (Flowerdew 1993. p.308). Some examples of genre suggested according to this school are: Recount, Procedure, Description, Explanation, and discourse. Though the new Rhetoric studies and Australian theories are applied independently of each other, they show considerable overlap, both focused on the role of the context and the social situation of the genre. The main difference is the prescriptiveness view of genre in Australian school (not in the Halliday's theory). On the other hand, the new rhetoric studies develop the dynamic quality of genres (Freedman \& Medway 1998). Furthermore, the ESP school or the Swalessian tradition focuses on the dynamic structure of genre (Conner 1993; Hicks 2000) and focuses on techniques to achieve it (Freedman \&Medway 1994; Kay and Dudley Evans1998; Swales 1990).

\section{Feez's Model of Writing Instruction}

As it was expressed, Feez's (1998) model of writing will be applied in this study. Figure 1 shows the model. The cycle shows the planning of classroom tasks by showing the process of learning a genre as a series of linked steps. Here, the teacher provides initial explicit knowledge and guided practice, moves to divide responsibility for developing texts, and gradually withdraws protect until the learner can do the activity by himself. Hyland (2017, p. 260) summarizes the main steps of the cycle as:

- "setting the context: revealing genre purposes and the settings in which it is commonly used;

- modeling: analyzing representative samples of the genre to identify its stages and key features and the variations which are possible;

- joint construction: guided, teacher-supported practice in the genre through tasks which focus on particular stages or functions of the text;

- independent construction: independent writing by students monitored by the teacher; and

- comparing: relating what has been learnt to other genres and contexts to understand how genres are designed to achieve particular social purposes".

"Each of these stages therefore seeks to achieve a different purpose, and as a result, is associated with different types of classroom activities and different teacher-learner roles" (Hyland, 2004, pp. 130-140). "The cycle is one way

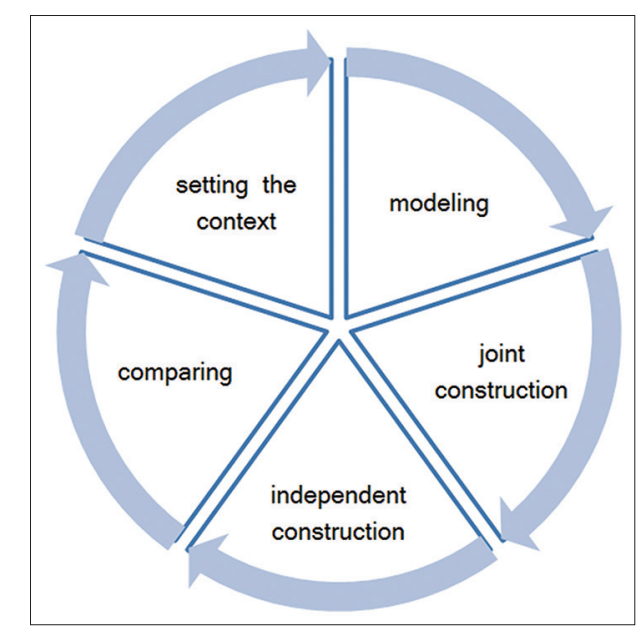

Figure 1. Feez's (1998) model 
of understanding the Five E's concept long familiar in science teaching, helping learners to engage, explore, explain, extend, and evaluate" (e.g. Trowbridge \& Bybee, 1990, p.145). The cycle is intended to allow learners to enter at any step according to their existing knowledge of the genre and to able teachers to come back to earlier steps of the cycle for revision aims.

\section{Empirical Studies}

Khatib and Mirzaii (2016) discovered the influence of using metalinguistic feedback and scaffolded genre-based teaching via consciousness-raising tasks on EFL learners' ability to write descriptive essay. To achieve this aim, two groups as feedback group and instruction group took part in their study. After pretesting, the researchers provided the participants with written metalinguistic explanations on their compositions or genre-based instruction. The results showed that the instruction group had more significant developments.

Sadeghi, Hassani and Hemmati (2013) studied the role of a genre-based instruction on ESP students' reading comprehension. They chose 116 homogenous participants in the field of biology as the participants of the study then they were divided into two groups; experimental and control groups. The experimental group was taught via genrebased instruction and the control groups was instructed by using a traditional one. Both groups had a 30 -item proficiency test of English and two 30-item tests of English reading comprehension. The results were analyzed by using t-test that showed the significant role of a genre-based instruction in developing the ESP learners' reading comprehension.

Shafizadeh and Sajedi (2013) studied the influence of genre consciousness raising and genre-based instruction on second language reading comprehension proficiency. 40 students took an IELTS test and were divided into two groups of low and high proficient according to their scores. Both groups had pre-and post-reading comprehension tests of narrative genre. Shafizadeh and Sajedi (2013, p.230) expressed that "genre-familiarity influences reading comprehension ability of the learners". Furthermore, it was expressed that "reading comprehension ability is influenced by the level of proficiency as well as the familiarity of the genres". Shafizadeh and Sajedi (2013, p.230) argues that "genre-familiarity and language proficiency are crucial for reading comprehension".

Crossley (2013) also argues about the influence of genre analysis pedagogy. He stresses on the role of different instructional approaches on writing. He asserts that "move analysis approach as an approach to genre analysis influence writing performance of the language learners than the chronotropic approach which is a non-genre-analysis approach" (p.146). Crossley (2013) offers that genre analysis methods be used in the English for Specific purposes (ESP).

In another study, Khatib and Mirzaii (2016) did a threestrand mixed study aimed at the empirical development of an analytic rating scale for scoring descriptive written by EFL learners. Their mixed study factor analyzed 172 ELT participants' analyses of the genre of descriptive, and content-analyzed 20 authentic and 30 inauthentic descriptive texts. Resulting from two meta-inferences made in the course of this study, the Analytic Rating Scale for EFL Descriptive Writing was constructed. Hopefully, using this scale led to more reliable scores and more valid interpretation.

Minaabad and Khoshkholgh (2012) study to explore the effect of genre-based instruction on English for specific purpose (ESP) for learners' reading comprehension ability and the correlation between their reading comprehension and their general English proficiency. So, they choose 150 BA students who were studying ESP in the field of computer engineering. The participants answered a version of GEP test (i.e. a 1961 version of Michigan test). Based on the results, the subjects were divided into two groups: high and low proficiency. Both groups were randomly divided into two experimental and control groups. The four groups (i.e. high level experimental, high level control, low level experimental, and low level control) received a six-session instruction and after that they had a posttest. A two-way ANOVA was applied for analyzing the results. Minaabad and Khoshkholgh (2012) showed that genre-based instruction effect learners' reading comprehension. Moreover, they concluded that there is positive relationship between learner's ESP reading comprehension achievement and general English proficiency.

\section{METHODOLOGY}

\section{Participants}

At the beginning of the study, the researcher got the consent forms from the participants and their instructors. Oxford Placement Test (OPT) was applied to select those whose score are between one standard deviation (+1SD) above the mean and one standard deviation (-1SD) below the mean. Based on the results of the OPT, 60 out of 80 Iranian EFL M.A. male and female students from two Azad universities in Tehran, Iran, were selected as the main participants of this study. A group of 60 male and female MA students took part in this study, who were passing academic writing course in two Azad universities of Tehran, Iran. The participants were between 23 and 35 years old. Then, the participants were divided into two groups, an experimental group and a control group.

\section{Instrumentation}

To collect data, the following instruments were used in this study:

\section{Oxford placement test}

To estimate the general language proficiency of the participants at the beginning of the study, and to have a homogenous sample, the Oxford Placement Test (OPT) was applied. The KR-21 formula was used to estimate the internal reliability of the test. This test consisted of 100 items in the form of multiple-choice questions, and students were supposed to choose the correct answer from among the alternatives. 


\section{Pretest}

A standard pretest was applied to investigate the participants' initial knowledge of writing skill. The purpose of this test was to investigate whether participants were homogeneous in their writing skill at the beginning of the study. This test consisted of two compositions. The participants were asked to write two compositions for descriptive writing. The topics of the writing compositions of the pretest were also reviewed by two faculty members to ensure the validity. Moreover, KR21 was conducted to ensure its reliability.

\section{Posttest}

This test consisted of two compositions. The only difference between this test and the pretest was that the sequence of the writing topics was changed to avoid "practice effect" (Bachman, 1990) on the part of the participants. The posttest was applied to estimate the progress of the experimental group via using genre-based teaching during the 16 sessions. It was necessary to express that the pretest and posttest were descriptive writing based on IELTS' writing test.

\section{Data Collection Procedure}

At the beginning of this study, an Oxford Proficiency Test (OPT) was administered to ensure the homogeneity of the participants. Then, 80 female and male MA EFL learners from two Azad universities of Tehran, Iran whose scores fell one SD above and below the mean were selected as main participants in this study. Having analyzed the data, the researcher selected 60 participants for the purpose of this study. Participants were divided into one experimental group and one control group each with 30 learners. The experimental group received the genres based instruction on descriptive writing. The treatment was given in 16 sequential sessions about 30 minutes at the beginning of each session. The control group received no special treatment and it was instructed based on traditional model of writing instruction. At the beginning of the study, a pretest on writing performance was administered to measure participants' initial knowledge. In this test, the two groups were given the same topics to write two compositions.

At the end of the study, a posttest was used to check the participants' knowledge in terms of descriptive writing after having been exposed to instruction. The participants' scores on the pretest and posttest were compared to estimate the amount of progress of participants within the group, and also the scores of the two groups were compared with each other to see the function of instruction.

\section{DATA ANALYSIS AND RESULTS}

\section{Findings of the First Research Question}

\section{The results of the analysis of learners' responses to the writing performance before using the genres based instruction as the treatment}

As Table 1 shows the mean and the standard deviation scores in writing performance pre-test for the experimental group are respectively 20.53 and 7.53 . The mean and the standard deviation scores in writing pre-test for the control group are respectively 20.21 and 7.48 . As it is clear, these two groups were at the same level at the beginning of this study.

A t-test was used to show the sameness of these two groups before using treatment.

As Table 2 shows the amount of $t$-observed $(t=2.21)$ is significant at the probability level of $\mathrm{p}=.062$ which is bigger than.05. So, it is clear that there is not any significant difference between control and experimental groups before using treatment.

\section{The results of the analysis of learners' responses to the writing performance after using the genres based instruction as the treatment}

Table 3 gives a summary of the learners' responses to the writing test after the treatment.

As is clear from Table 3, the mean and the standard deviation scores in writing posttest for experimental group are respectively 27.49 and 6.12 . The mean and the standard deviation scores in writing performance posttest for control group are respectively 18.30 and 5.50 . By comparing the means of the post-test, it can be expressed that the experimental group did better on the posttest. So, the researcher can conclude that genres based instruction as the treatment worked well.

\section{DISCUSSION AND CONCLUSION}

\section{Discussion}

To do this study, the researcher chose 60 students by applying OPT as a proficiency test. Then, the participants were divided into experimental and control groups. At the beginning of the study, a pretest was given to learners to estimate their writing ability. The analysis of the results showed that learners in both groups were at the same level of ability.

Table 1. Descriptive statistics of the learners' responses to the writing performance before the treatment

\begin{tabular}{lccc}
\hline Groups & N & MEAN & SD \\
\hline Experimental & 30 & 20.53 & 7.53 \\
Control & 30 & 20.21 & 7.48 \\
\hline
\end{tabular}

Table 2. The results of the t-test for the writing performance test

\begin{tabular}{lcccccc}
\hline Groups & No. & Mean & SD & df & t & p \\
\hline Experimental & 30 & 20.53 & 7.53 & 58 & 2.21 & .062 \\
Control & 30 & 20.21 & 7.48 & & & \\
\hline
\end{tabular}

Table 3. Descriptive statistics of the learners' responses to the writing performance test after the treatment

\begin{tabular}{llcc}
\hline Groups & N & MEAN & SD \\
\hline Experimental & 30 & 27.49 & 6.12 \\
Control & 30 & 18.30 & 5.50 \\
\hline
\end{tabular}


Next, participants in the experimental group were taught via genres based instruction but learners in control group were instructed via traditional methods. Finally, the same pretest was given to learners in both groups as posttest and the analysis of the results showed that learners in experimental group did better than learners in control group and it was concluded that genres based instruction as treatment worked well.

The results of this study are in line with the study by Akyürek (2003) who found that genres based instruction can be a good strategy for improving learners writing ability. Also, another study by Amer (2002) presented that female learners were better in writing performance by using genres based instruction.

\section{Implications for English Teachers and Learners}

By conducting this study, the researcher wanted to answer the research question and found some implications for English teachers and learners. So, it can be recommended that teachers should consider genres based instruction for improving writing skills. By using these strategies L2 learners can enhance their writing abilities through meaningful learning and they will have more confidence.

\section{REFERENCES}

Ahn, H. (2012). Teaching writing skills based on a genre approach to L2 primary school students: An action research. English Language Teaching, 5(2), 2-16.

Akyürek. (2003). "Strategy instruction in reading comprehension An intervention study for students with learning disabilities", in Learning Disabilities: A ontemporaryJournal, 5: 41-57.

Amer, A. (2002). Advanced vocabulary instruction in EFL. The Internet TESL Journal, 3(11). Retrieved January 20, 2010 from http://iteslj.org/Articles/Amer-Vocabulary

Bhatia, V. K. (2004). Worlds of Written Discourse. London: Continuum.

Carstens, A. (2009). The effectiveness of genre-based approaches in teaching academic writing: Subject-specific versus cross-disciplinary emphases. Unpublished doctoral dissertation, Pretoria, South AfricaUniversity.

Ellis, R. (1997). SLA research and language teaching. Oxford: Oxford University Press.

Ephraim, K. (2009). Reading Comprehension Instruction for Expository Text in Elementary Education. Unpublished thesis. Virginia, US. Retrieved on February, 2017 from http://digitalcommons.liberty.edu/cgi/viewcontent. cgi? article $=1183 \&$ context $=$ honors

Holmes, R. (1997). Genre analysis, and the social sciences: an investigation of the structure of research article discussion sections in three disciplines. English for Specific Purposes, 16(4), 321-337. http://dx.doi.org/10.1016/ S0889-4906(96)00038 5

Hyland, K. (2002). Teaching and researching writing. London: Longman.

Hyon, S. (1996). Genre in Three Dimensions. Implications for ESL. TESOL Quarterly, 30, (4), pp. 693-716.

Hyland, K. (2007)." Metadiscourse: mapping interactions in academic writing". Nordic journal of English Studies. Special Issue on Metadiscourse.9(2),125-143.

Jodairi Pineh, A. (2017). Moving against the grain: Exploring genre-based pedagogy in a new context. Journal of research in Applied Linguistics,8 (2),136-158.

Khatib, M, \& Alipour, M. (2007). How explicit instruction makes a difference: metadiscourse markers and EFL learners' reading comprehension skill. Journal of College Reading and Learning,38(1),35-52.

Khatib, M, \& Mirzaii, M. (2016). Developing an Analytic Scale for Scoring EFL Descriptive Writing. Journal of English Language and Learning Tabriz University,17, 49-73.

Liu, F. (2012). Genre analysis of American presidential inaugural speech. Theory and Practice in Language Studies, 2(11), 2407-2411.

Luo, J., \& Huang, T. Y. (2015). Genre-based analysis of American tourism brochures. Open Journal of Social Sciences, 3, 200-208.

McCarthy, M., \& Carter, R. (1994). Language as discourse: Perspectives for language teaching. London: Longman.

Paltridge, B. (2007). Approaches to genre in ELT. International handbook of English language teaching, 15, 931-943.

Pretoria. Elashri, I. I. (2013). The effect of the genre-based approach to teaching writing on the EFL Al-Azhar secondary students' writing skills and their attitudes towards writing. Retrieved January 12, 2018, from files. eric.ed.gov/full text/ED539137.pdf

Swales, J. M. (1990). Genre analysis. English in academic and research settings. Cambridge: Cambridge University Press.

Ting, S. H., Campbell, Y. M., Law, L., \& Poh, H. H. (2013). Explanations without a purpose? Genre-based instruction and academic writing. Journal of Academic Language \& Learning, 7(1), 26-39. 